\title{
Possible Side Reactions Due to Water in Emulsion Polymerization by Late Transition Metal Complexes II: Deactivation of the Catalyst by a Wacker-Type Reaction
}

\author{
Roger L. DeKock, ${ }^{\dagger}$ Iordan H. Hristov ${ }^{\ddagger}$ Grant D. W. Anderson ${ }^{\ddagger}$ \\ Inigo Göttker-Schnetmann, ${ }^{\S}$ Stefan Mecking, ${ }^{\S}$ and Tom Ziegler* ${ }^{*}$ \\ Department of Chemistry and Biochemistry, Calvin College, 3201 Burton Street SE, \\ Grand Rapids, Michigan 49546-4388, Department of Chemistry, University of Calgary, \\ 2500 University Drive NW, Calgary, Alberta, Canada T2N 1N4, and Faculty of Science, \\ University of Konstanz, Universitätsstrasse 10, D-78464 Konstanz, Germany
}

\begin{abstract}
The transition metal catalyzed ethylene polymerization in water suspensions has been increasingly successful in the last couple of years. Water, however, adversely affects the polymerization process by deactivating the catalyst in a Wacker-type reaction. The cationic $\mathrm{Pd}$ (II)-diimine Brookhart catalyst 1 is studied here by a combination of quantum mechanics and molecular mechanics to determine the nature of the decomposition reaction. The study considers the decomposition process to take place in two stages. In the first stage, a coordinated olefin is attacked by a hydroxide group to ultimately produce a $\beta$-hydroxy-ethyl complex 2 . The second step represents a decomposition to acetaldehyde and $\operatorname{Pd}(0)$, the latter in the form of palladium black. For the attack of $\mathrm{OH}$ on the coordinated ethylene in $\mathbf{1}$, both an internal path involving transfer from a palladium-coordinated $\mathrm{OH}$ group produced from hydrolysis of a $\mathrm{Pd}-\mathrm{CH}_{3}$ bond and an external path based on attack of $\mathrm{H}_{2} \mathrm{O}$ on coordinated ethylene were considered. Both paths are found to be feasible. For the second stage the most promising decomposition mode involves isomerization of $\mathbf{2}$ to the $\alpha$-hydroxy-ethyl complex $\mathbf{5}$ followed by abstraction of a proton from the $\mathrm{C}-\mathrm{OH}$ link to produce the $\mathrm{Pd}(0)-\eta^{2}-$ acetaldehyde complex 12. Finally, 12 releases acetaldehyde under the deposition of $\operatorname{Pd}(0)$ as palladium black.
\end{abstract}

\section{Introduction}

One of us ${ }^{1}$ has reported coordination polymerization of ethylene in aqueous emulsion or suspension by cationic palladium(II) diimine complexes (introduced as olefin polymerization catalysts by Brookhart et al. ${ }^{2}$ ). The catalyst is protected from access of water in the initial stages of the reaction by being employed as a waterinsoluble solid of relatively large particle size, and latterly by being encapsulated in the hydrophobic amorphous polyethylene formed.

Experiment ${ }^{1 b}$ has also shown that although the $\operatorname{Pd}(\mathrm{II})$-based Brookhart catalyst of Figure 1 is stable in aqueous solution for days, the addition of ethylene leads to immediate decomposition to palladium black, hence

* To whom correspondence should be addressed. E-mail: ziegler@ ucalgary.ca.

$\dagger$ Calvin College.

\# University of Calgary.

$\S$ University of Konstanz.

(1) (a) Held, A.; Bauers, F. M.; Mecking, S. Chem. Commun. 2000, 301-2. (b) Held, A.; Mecking, S. Chem.-Eur. J. 2000, 6, 4623. (c) Bauers, F. M.; Mecking, S. Macromolecules 2001, 34, 1165. (d) Bauers, F. M.; Mecking, S. Angew. Chem . 2001, 113, 3112; Angew. Chem., Int Ed. 2001, 40, 3020. (e) Bauers, F. M.; Chowdhry, M. M.; Mecking, S. Macromolecules 2003, 36, 6711. (f) Bauers, F. M.; Thomann, R.; Mecking, S. J. Am. Chem. Soc. 2003, 125, 8838. (g) Zuideveld, M. A.; Wehrmann, P.; Röhr, C.; Mecking, S. Angew. Chem. 2004, 116, 887; Angew. Chem., Int. Ed. 2004, 43, 869-73.

(2) Johnson, L. K.; Killian, C. M.; Brookhart, M. J. Am. Chem. Soc. 1995, 117 (23), 6414-6415.

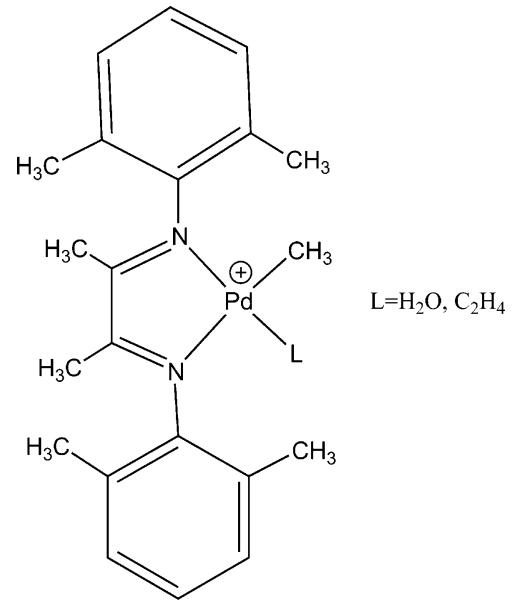

Figure 1. Schematic structures of the catalyst species investigated.

the necessity for emulsification of the catalyst precursor; the reason for this decomposition has not been clarified. Although no organic products were isolated in the catalyst decomposition process, it has been suggested that the decomposition occurs by a Wacker-type reaction. ${ }^{3-6}$

(3) Siegbahn, P. E. M. J. Am. Chem. Soc. 1995, 117 (19), 54095410

(4) Siegbahn, P. E. M. J. Phys. Chem. 1996, 100 (35), 14762-14680. 
Scheme 1. Proposed Mechanism for the Production of Aldehyde at the Pd Center
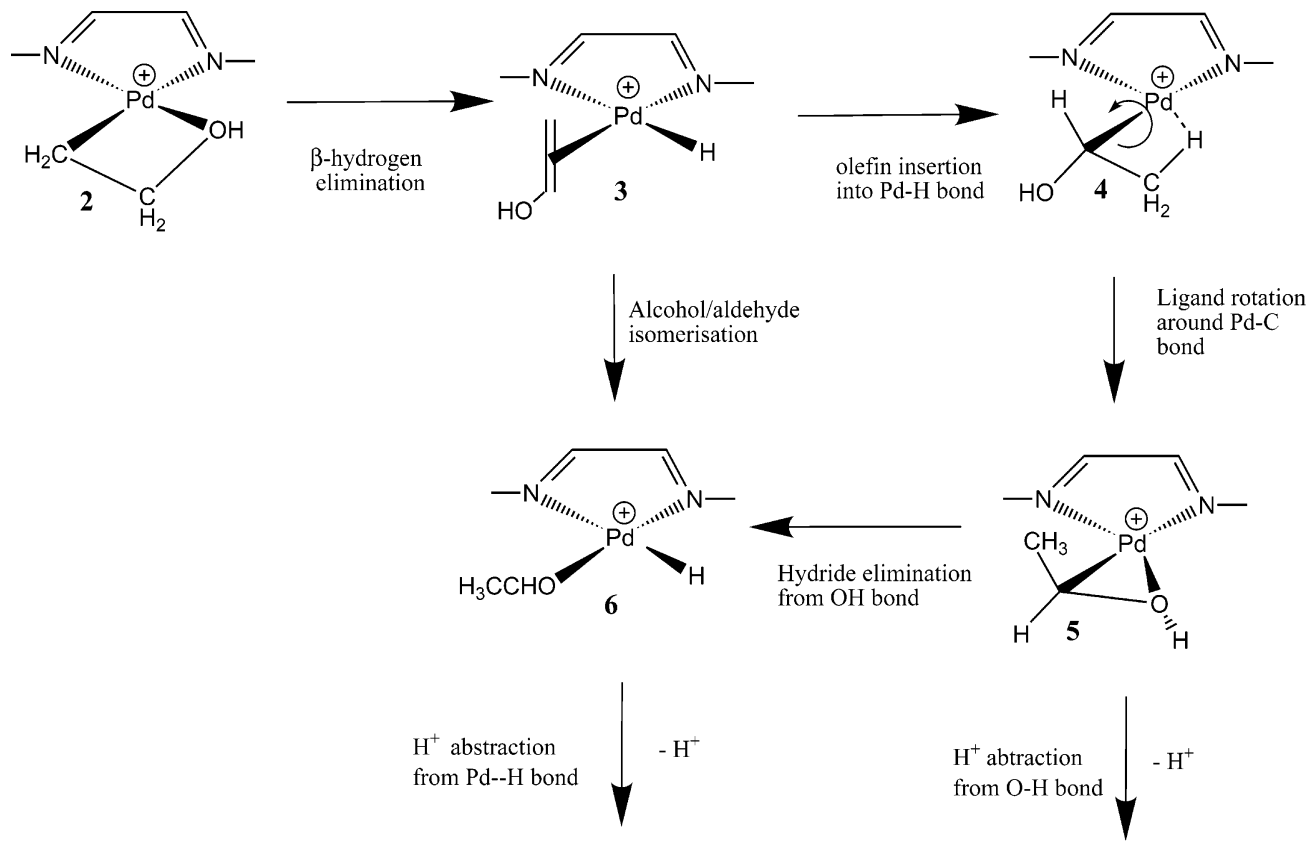

$\mathrm{Pd}^{(0)}+\mathrm{OCHCH}_{3}$

$\mathrm{Pd}^{(0)}+\mathrm{OCHCH}_{3}$

We shall in the following consider the decomposition as comprised of two stages. In the first stage the original Brookhart catalyst $\mathbf{1}$ is converted into a $\beta$-hydroxy-ethyl complex 2 by a water molecule.

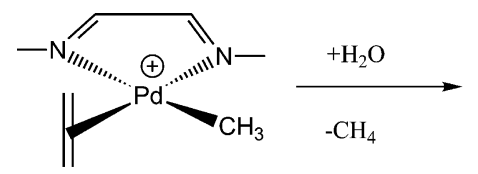

1

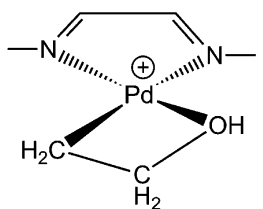

This process can be accomplished by an inner sphere reaction where the $\mathrm{M}-\mathrm{CH}_{3}$ bond of the Brookhart catalyst $\mathbf{1}$ is hydrolyzed by $\mathrm{H}_{2} \mathrm{O}$ :

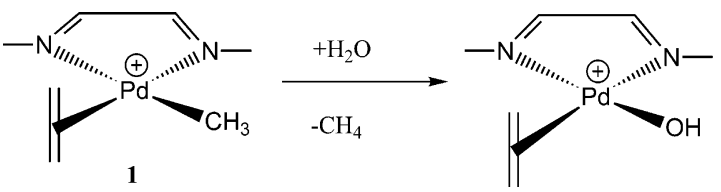

followed by insertion of ethylene into the $\mathrm{Pd}-\mathrm{OH}$ bond:

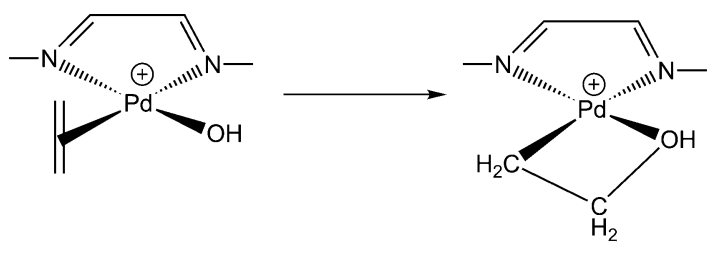

Alternatively, an external $\mathrm{H}_{2} \mathrm{O}$ can carry out a nucleophilic attack on the coordinated ethylene in $\mathbf{1}$, leading

(5) (a) Kragten, D. D.; van Santen, R. A. J. Phys. Chem. A 1999 103 (15), 2756-2765. (b) Kragten, D. D.; van Santen, R. A. J. Phys. Chem. A 1999, 103 (1), 80-88.

2420 . to a hydrido hydroxy-ethylene complex $\mathbf{3}$ :

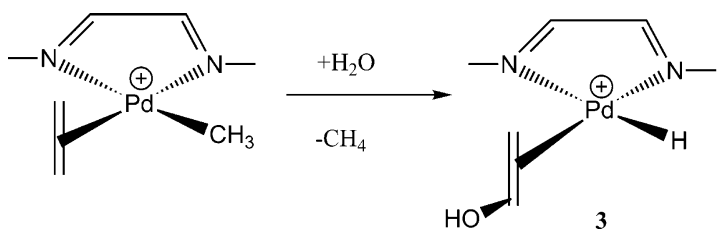

The complex 3 can subsequently rearrange to $\mathbf{2}$ by reinsertion of hydroxy-ethylene into the $\mathrm{Pd}-\mathrm{H}$ bond:

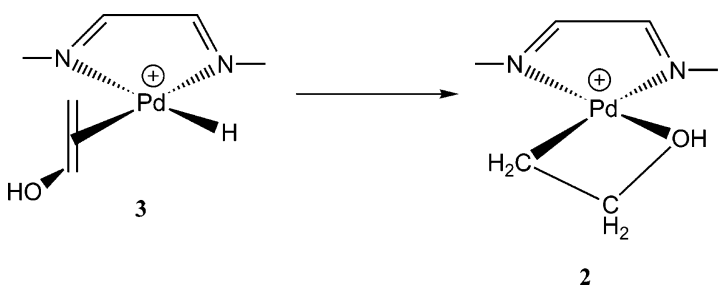

We have already investigated the hydrolysis step of eq 2 in a previous study. ${ }^{7}$

At the second stage of the decomposition, the $\beta$ hydroxy-ethyl complex 2 can rearrange to the $\alpha$ hydroxy-ethyl isomer $\mathbf{5}$ followed by proton abstraction to form $\mathrm{CH}_{3} \mathrm{CHO}$ and $\mathrm{Pd}(0)$; see Scheme 1. Alternatively, 2 might isomerize to the hydrido aldehyde complex 6 again followed by proton abstraction to form $\mathrm{CH}_{3} \mathrm{CHO}$ and $\mathrm{Pd}(0)$; see Scheme 1 .

This account is organized as follows. We first examine the conversion of the Brookhart catalyst to the $\beta$ hydroxy-ethyl complex 2 (eq 1) either by the internal pathway involving initial hydrolysis (eqs 2,3 ) or by the direct nucleophilic attack of an external water molecule (eqs 4,5$)$. After that, we carry out an initial exploration of the potential energy surface for the isomerization of $\mathbf{2}$ to either $\mathbf{5}$ or $\mathbf{6}$ (Scheme 1) followed by an exploration

(7) Hristov, I. H.; DeKock, R. L.; Anderson, G. D. W.; GöttkerSchnetmann, I.; Mecking, S.; Ziegler, T. To be submitted. 
of pathways that can convert $\mathbf{5}$ and $\mathbf{6}$ into aldehyde and $\operatorname{Pd}(0)$ by proton abstraction, Scheme 1 . We finally comment briefly on water-assisted isomerization pathways leading from $\mathbf{2}$ to either $\mathbf{5}$ or $\mathbf{6}$.

\section{Computational Method}

All calculations were carried out using the Amsterdam Density Functional (ADF 2.3.3) program $^{8}$ developed by Baerends et al. ${ }^{9}$ and vectorized by Ravenek. ${ }^{10}$ The numerical integration scheme applied for the calculations was developed by te Velde et al. ${ }^{11}$ The geometry optimization procedure was based on the method of Versluis and Ziegler. ${ }^{12}$ Geometry optimizations were carried out and energy differences determined using the local density approximation of Vosko, Wilk, and Nusair (LDA VWN) ${ }^{13}$ augumented with the nonlocal gradient correction PW91 from Perdew and Wang. ${ }^{14}$ Relativistic corrections were added using a scalar-relativistic Pauli Hamiltonian. ${ }^{15}$ All atoms were described by a core double- $\zeta$, valence triple- $\zeta$, polarized basis set. Non-hydrogen atoms were assigned a relativistic frozen-core potential, treating as core shells up to and including $3 \mathrm{~d}$ for $\mathrm{Pd}$; 1 s for $\mathrm{C}, \mathrm{N}$, and $\mathrm{O}$. A set of auxiliary s, p, d, f, and g functions, centered on all nuclei, was used to fit the molecular density and to represent the Coulomb and exchange potentials accurately in each SCF cycle. The counterions have not been included in the model for simplicity. Solvation energies were calculated from gas phase structures by using the conductor-like screening model $(\mathrm{COSMO})^{16}$ that has been implemented recently into the ADF program. ${ }^{17}$ The solvation calculations were performed with a dielectric constant of 2.379 for toluene and 78.36 for water. The radii used for the atoms (in $\AA$ ) are as follows: H 1.16, S 1.7, C 2.3, O 1.3, N 1.4, P 2.4, Pd 1.38. Some of these values were obtained previously by optimization using least-squares fitting to experimental solvation energies. ${ }^{18}$ Transition states were fully optimized using the algorithm of Banerjee et al. ${ }^{19}$ starting from the structures obtained by linear transit calculations. No symmetry constraints were used. The Brookhart system was calculated using the QM/MM method. ${ }^{20}$ An augmented AMBER95 force field ${ }^{21}$ was utilized to describe the molecular mechanics potential. The separation of the catalyst molecule into a QM and MM part is illustrated in Scheme 2.

(8) Amsterdam Density Functional program; Division of Theoretical Chemistry, Vrije Universiteit, De Boelelaan 1083, 1081 HV Amsterdam, The Netherlands; www.scm.com.

(9) Baerends, E. J.; Ellis, D. E.; Ros, P. Chem. Phys. 1973, 2 (1), 41-59.

(10) Ravenek, W. In Algorithms and Applications on Vector and Parallel Computers; te Riele, H. J. J., Dekker, T. J., van de Horst, H. A., Eds.; Elsevier: Amsterdam, 1987.

(11) Boerrigter, P. M.; Velde, G. T.; Baerends, E. J. 3-Dimensional Numerical-Integration for Electronic-Structure Calculations. Int. J. Quantum Chem. 1988, 33 (2), 87-113.

(12) Versluis, L.; Ziegler, T. J. Chem. Phys, 1988, 88 (1), 322-328.

(13) Vosko, S. H.; Wilk, L.; Nusair, M. Can. J. Phys. 1980, 58, 1200.

(14) Perdew, J. P.; Chevary, J. A.; Vosko, S. H.; Jackson, K. A.; Pederson, M. R.; Singh, D. J.; Fiolhais, C. Phys. Rev. B 1992, 46 (11), 6671-6687.

(15) Snijders, J. G.; Baerends, E. J.; Ros, P. Mol. Phys. 1979, 38 (6), 1909-1929.

(16) Klamt, A.; Schuurmann, G. J Chem Soc., Perkin Trans. 2 1993, (5), 799-805

(17) Pye, C. C.; Ziegler, T. Theor. Chem. Acc. 1999, 101 (6), 396408.

(18) Marcus, Y. J. Chem. Soc., Faraday Trans. 1991, 87 (18), 29952999.

(19) (a) Banerjee, A.; Adams, N.; Simons, J.; Shepard, R. J. Phys. Chem. 1985, 89, 52. (b) Fan, L.; Ziegler, T. J. Chem. Phys. 1990, 92 3645. Velde, G. T.; Bickelhaupt, F. M.; Baerends, E. J.; Guerra, C. F.; Van Gisbergen, S. J. A.; Snijders, J. G.; Ziegler, T. J. Comput. Chem. 2001, 22 (9), 931-967.

(20) Woo, T. K.; Cavallo, L.; Ziegler, T. Theor. Chem. Acc. 1998, 100 (5-6), 307-313.

(21) Cornell, W. D.; Cieplak, P.; Bayly, C. I.; Gould, I. R.; Merz, K. M.; Ferguson, D. M.; Spellmeyer, D. C.; Fox, T.; Caldwell, J. W.; Kollman, P. A. J. Am. Chem. Soc. 1995, 117 (19), 5179-5197.
Scheme 2. QM/MM Partition of the Molecule Structure

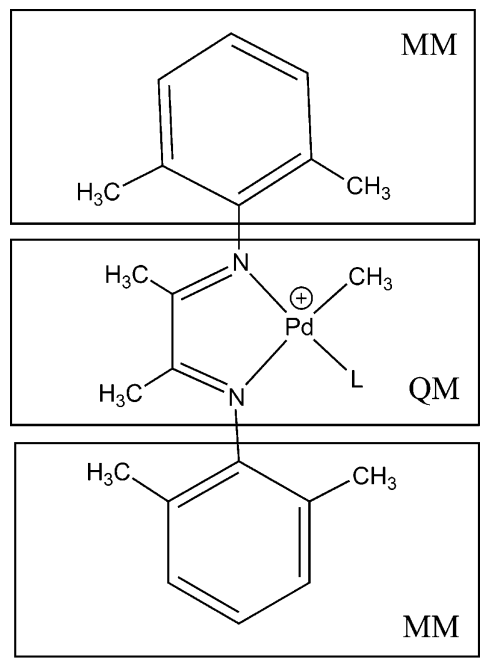

The bond length for $\mathrm{C}-\mathrm{N}$ that links the QM and MM parts has been calculated for the generic compound with a full QM calculation. The capping atoms used were hydrogens. Each link bond has a constant parameter $\alpha$ associated with it, ${ }^{22}$ which was 1.41 for the $\mathrm{C}-\mathrm{C}$ bonds in the Brookhart system.

\section{Results and Discussion}

We shall discuss a possible mechanism for the observed decomposition of the $\mathrm{Pd}(\mathrm{II})$-based Brookhart catalyst in aqueous media after addition of ethylene. ${ }^{1 b}$ The decomposition involves ${ }^{1 \mathrm{~b}}$ the reduction of the metal center from $\mathrm{Pd}(\mathrm{II})$ to $\mathrm{Pd}(0)$. We shall consider this decomposition as a two-stage process consisting of a conversion of the Brookhart catalyst 1 to the $\beta$-hydroxyethyl complex 2 (eq 1 ) followed by a decomposition of $\mathbf{2}$ to $\operatorname{Pd}(0)$ and acetaldehyde, Scheme 1 . We start by investigating the conversion of the Brookhart catalyst $\mathbf{1}$ to the $\beta$-hydroxy-ethyl complex $\mathbf{2}$ (eq 1 ) either by the internal pathway involving initial hydrolysis (eqs 2,3) or by the direct nucleophilic attack of an external water molecule (eqs 4, 5).

Conversion of 1 to 2 after Initial Hydrolysis of the $\mathrm{Pd}-\mathrm{CH}_{3}$ Bond in 1 without External Water Assistance. The process is illustrated in Figure 2. Initially a water molecule replaces ethylene in $\mathbf{1}$ to form the aqua complex 7. Complex $\mathbf{7}$ is $6.3 \mathrm{kcal} \mathrm{mol}^{-1}$ higher in energy ${ }^{7}$ than the catalyst resting state $\mathbf{1}$. After that, a proton is transferred from the coordinated water to the methyl group in $\mathbf{7}$ to produce the methane adduct 8. Relative to the catalyst resting state $\mathbf{1}$, the barrier for this process is as high as $34.6 \mathrm{kcal} \mathrm{mol}^{-1}$ and the heat of reaction is $19.4 \mathrm{kcal} \mathrm{mol}^{-1}$. The subsequent substitution of the weakly bound methane in 8 with a strongly coordinating ethylene in complex 10 results in a considerable stabilization of $24.5 \mathrm{kcal} \mathrm{mol}^{-1}$. The facile rotation of ethylene in $\mathbf{1 0}$ from an orientation perpendicular to the coordination plane of the complex to an in-plane orientation followed by insertion into the $\mathrm{Pd}-$ $\mathrm{OH}$ bond leads to the $\beta$-hydroxy complex 2 with an external barrier of $12.6 \mathrm{kcal} \mathrm{mol}^{-1}$ and a reaction enthalpy of $-3.4 \mathrm{kcal} \mathrm{mol}^{-1}$.

Conversion 1 to 2 after Initial Hydrolysis of the $\mathrm{Pd}-\mathrm{CH}_{3}$ Bond in 1 with External

(22) Woo, T. K. Ph.D. Thesis, University of Calgary, Canada, 1998. 


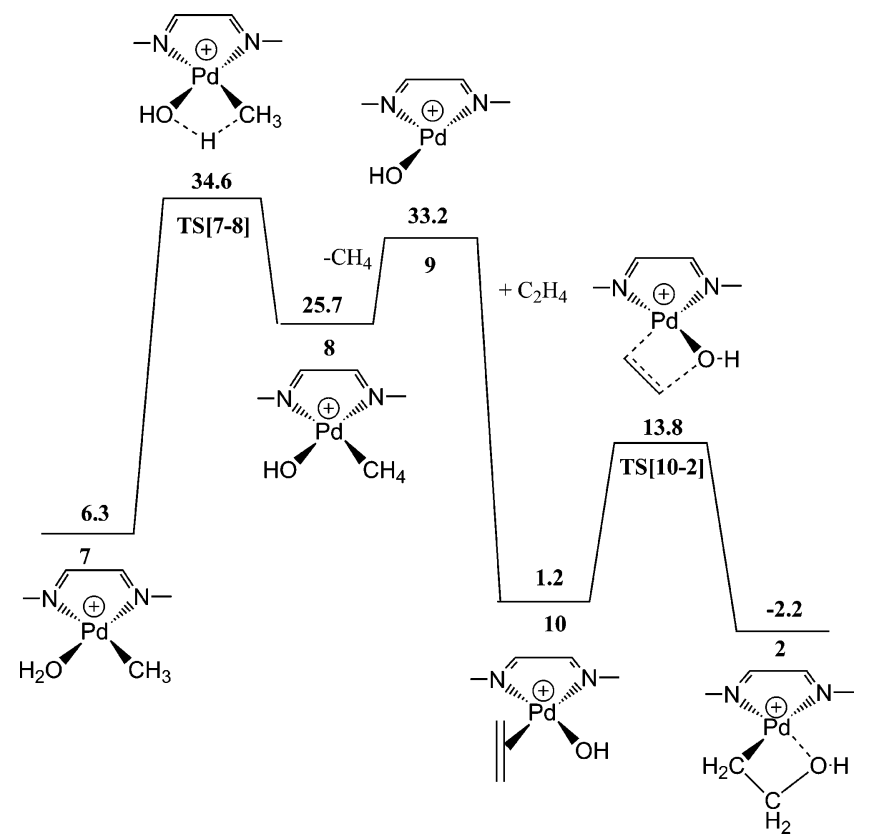

Figure 2. Conversion of $\mathbf{1}$ to $\mathbf{2}$ after initial hydrolysis of the $\mathrm{Pd}-\mathrm{CH}_{3}$ bond in $\mathbf{1}$ without external water assistance.

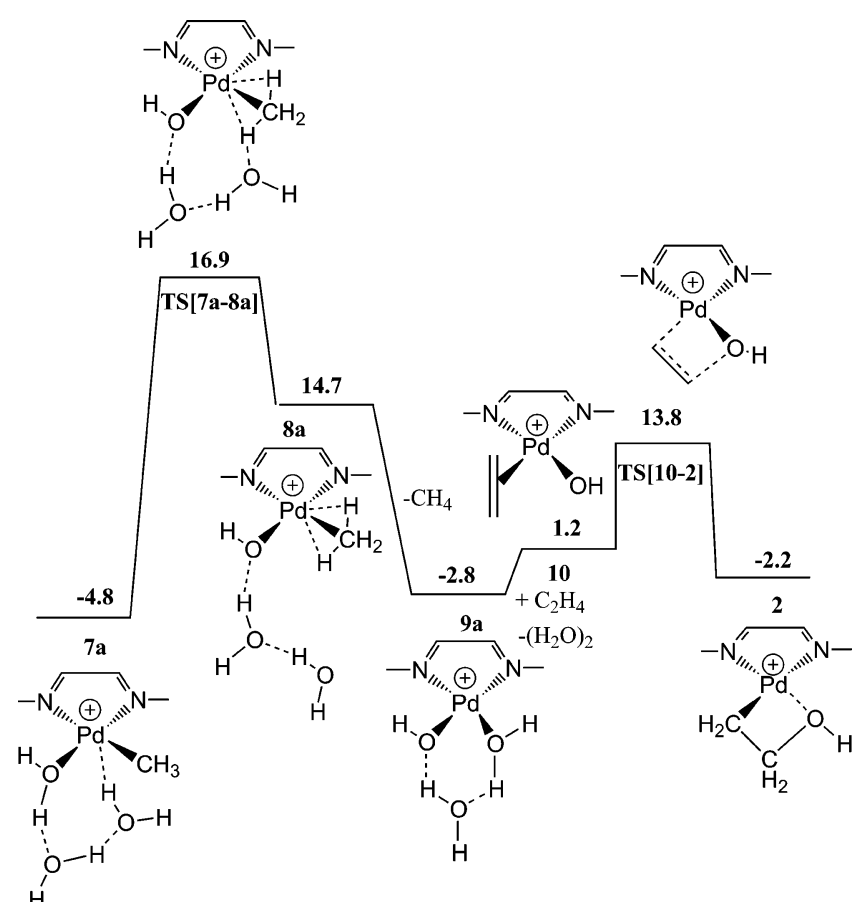

Figure 3. Conversion of $\mathbf{1}$ to $\mathbf{2}$ after initial hydrolysis of the $\mathrm{Pd}-\mathrm{CH}_{3}$ bond in $\mathbf{1}$ with external water assistance.

WaterAssistance. The process illustrated in Figure 2 has a rather high barrier of $34.6 \mathrm{kcal} \mathrm{mol}^{-1}$ for the hydrolysis step $\mathbf{7}$ to $\mathbf{8}$. For this reason a slight modification to the hydrolysis mechanism, involving the inclusion of an additional two solvent water molecules in the active site, shown in Figure 3, was studied. It was reported by Siegbahn ${ }^{4}$ that water chains significantly lower the calculated barriers for the Wacker process, and we wished to ascertain whether using a water chain model would have a similar effect on the hydrolysis barrier for the Brookhart system.

In this mechanism two water molecules bind to $\mathbf{7}$ such that a chain of three water molecules is attached to the

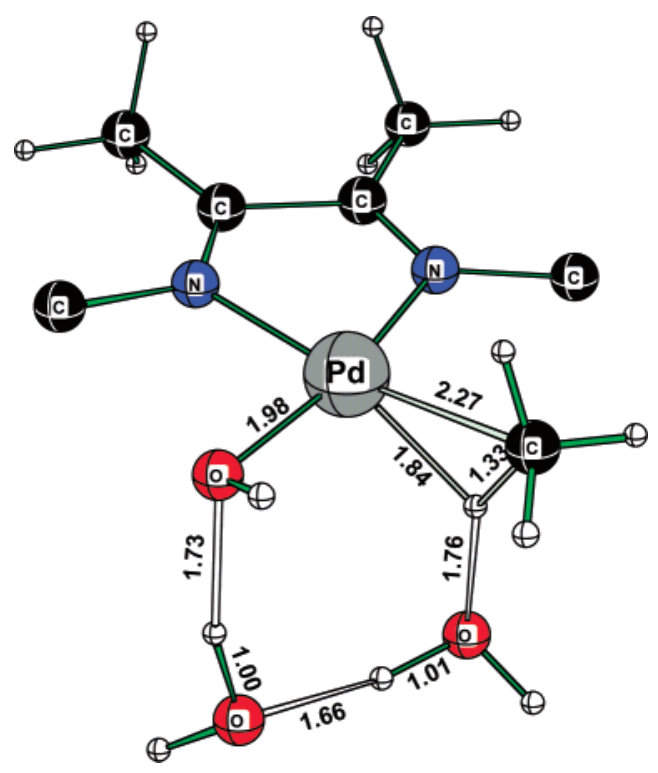

Figure 4. Transition state structure for the solventassisted internal hydrolysis of the Pd Brookhart catalyst 1.

complex, with the tail hydrogen atom of the chain being weakly bound to the $\mathrm{Pd} \mathrm{d}_{z^{2}}$ orbital, to give complex $\mathbf{7 a}$; see Figure 3. This step is exothermic by $11.1 \mathrm{kcal} \mathrm{mol}^{-1}$, and $\mathbf{7 a}$ has an energy of $-4.8 \mathrm{kcal} \mathrm{mol}^{-1}$ relative to the resting state $\mathbf{1}$. The first water molecule then provides the hydroxyl group to the metal, and the third water molecule provides the proton to the methyl group, with the central water molecule providing the bridge for the "proton shuttle" transfer of the proton. The methyl group is thus hydrolyzed to give the agostic methanebound structure 8a, which then evolves methane to afford structure $\mathbf{9 a}$ with the tail end of the water chain bound to the palladium coordination site vacated by the methane ligand. Two water molecules are then lost back to the solvent as an ethene molecule binds to the palladium center to give structure 10, from which $\mathbf{2}$ is reached as in the unassisted mechanism of Figure 2.

The transition state for the hydrolysis, TS[7a-8a], shown in Figure 4, is distinctly product-like, as would be expected from an endothermic process, with the two additional water molecules sited at long hydrogen bonding distances from the hydroxyl and (nearly fully formed) agostically bound methane ligand.

This solvent-assisted mechanism lowers the energy of the hydrolysis transition state to $16.9 \mathrm{kcal} \mathrm{mol}^{-1}, 17.7$ $\mathrm{kcal} \mathrm{mol}^{-1}$ lower than the barrier found without the solvent assistance. Loss of the methane molecule to give the hydroxyl/water-chain-ligated complex 9a is exothermic by $17.5 \mathrm{kcal} \mathrm{mol}^{-1}$, giving a structure only $2.0 \mathrm{kcal}$ $\mathrm{mol}^{-1}$ higher in energy than 7a. Displacement of the two water molecules by an ethylene molecule to give $\mathbf{1 0}$ is endothermic by a further $4.0 \mathrm{kcal} \mathrm{mol}^{-1}$, making the total process endothermic by $6.0 \mathrm{kcal} \mathrm{mol}^{-1}$.

Both enthalpic and entropic costs of taking two water molecules from the aqueous solution and binding them to $\mathbf{7}$ must be taken into account when considering whether this solvent-assisted mechanism provides a lower energy route (Figure 4) than the unassisted pathway, Figure 2. We take the position that the entropic penalty should be minimal $\left(3-5 \mathrm{kcal} \mathrm{mol}^{-1}\right.$ for $\left.\left(\mathrm{H}_{2} \mathrm{O}\right)_{2}\right)$ as the water dimer moves from one ordered 


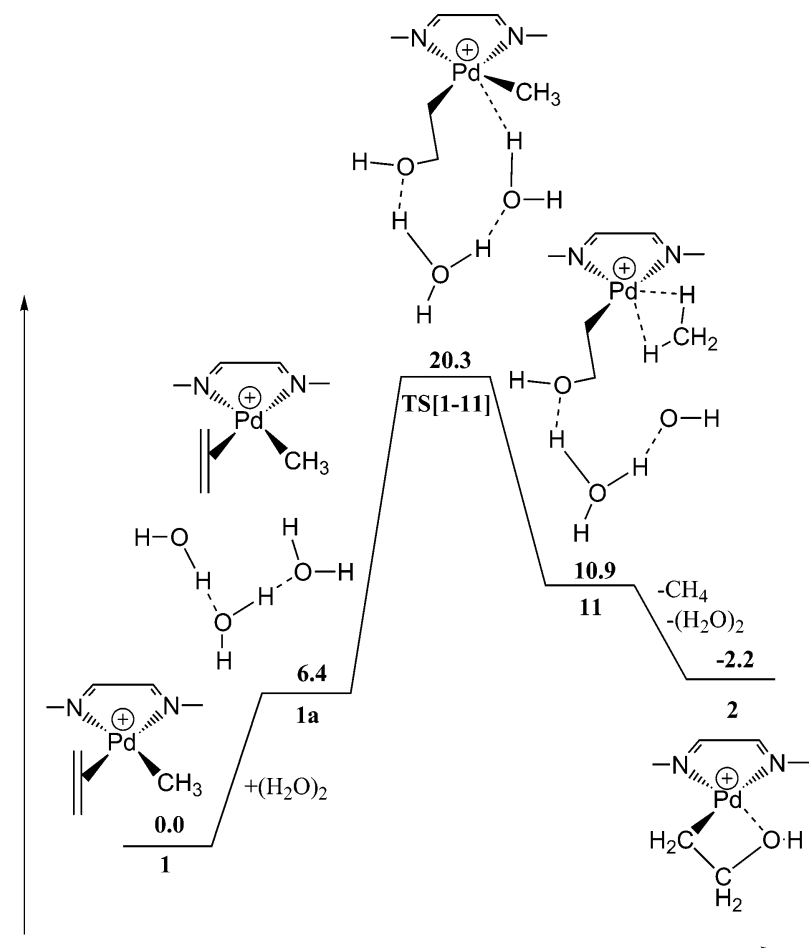

Figure 5. Energetics for conversion of $\mathbf{1}$ to $\mathbf{2}$ by external water attack on coordinated ethylene.

environment in bulk water to another ordered state where $\mathbf{7 a}$ is solvated. Also the enthalpic cost is likely minimal $\left(3-5 \mathrm{kcal} \mathrm{mol}^{-1}\right.$ for $\left.\left(\mathrm{H}_{2} \mathrm{O}\right)_{2}\right)$, as the energy required to remove the water dimer is compensated for by the bonding energy to the complex $7\left(11 \mathrm{kcal} \mathrm{mol}^{-1}\right)$ and residual hydrogen bonds between the dimer and the bulk water. Thus enthalpic and entropic factors might raise the barrier of water-assisted hydrolysis by $5-10$ $\mathrm{kcal} \mathrm{mol}^{-1}$. However, even then the assisted hydrolysis mechanism in Figure 3 would be favored.

Conversion of 1 to 2 after Direct Nucleophilic Attack of Water on Ethylene with External Water Assistance. In this mechanism, a water chain approaches the ethylene ligand and $\mathrm{Pd} \mathrm{d}_{z}{ }^{2}$ orbital, in a manner similar to that reported by Siegbahn ${ }^{4}$ for the Wacker process to give 1a; see Figure 5. Siegbahn also discussed in an earlier paper ${ }^{3}$ that use of a single water molecule does not lead to an accurate description of the nucleophilic attack, due to charge separation; therefore the water chain model is employed to yield the most realistic results. The oxygen head of the water chain then performs a nucleophilic attack on the ethylene ligand, while the methyl ligand is simultaneously attacked by the $\mathrm{Pd} \mathrm{d}_{z}{ }^{2}$ bound hydrogen end of the water chain to give an agostically bound methane ligand and two water molecules hydrogen bonded to the oxygen of the $\beta$-hydroxy-ethyl group (11). The next step is loss of the methane and two additional water molecules to give the $\beta$-hydroxy-ethyl complex 2. The energy profile for these three steps is shown in Figure 5.

The approach of the water chain, to give structure 1a, is endothermic by $6.4 \mathrm{kcal} \mathrm{mol}^{-1}$ and results in the structure shown in Figure 6. The large oxygen-carbon and hydrogen-palladium distances are as expected, given that the initial binding of the water chain is a weak interaction, with an $\mathrm{O}-\mathrm{C}$ distance of $3.12 \AA$, $\mathrm{H}-\mathrm{Pd}$ distance of $2.63 \AA$, and negligible lengthening of
$\mathrm{O}-\mathrm{H}$ distances or shortening of hydrogen bond distances within the chain compared to the initial structure. The rearrangement to structure $\mathbf{1 1}$ from $\mathbf{1 a}$ via the transition state TS[1a-11] (Figure 6) has an internal barrier of $13.9 \mathrm{kcal} \mathrm{mol}^{-1}$, Figure 6 . As would be expected for an endothermic reaction, the transition state is distinctly more product- than reactant-like, with the ethylene ligand rotated $90^{\circ}$ compared to complex 1a and bound in a distinctly asymmetric manner to the palladium atom; the ethylene carbon-carbon bond lengthened by $0.14 \AA$. This is consistent with work reported by Eisenstein and Hoffmann, ${ }^{23}$ which showed that nucleophilic attack on a bound ligand depends on the ligand adopting an asymmetric geometry so that there is a significant buildup of positive charge on one of the carbon atoms, making it more prone to nucleophilic attack.

The water chain in transition state TS[1a-11] does not differ significantly from that found for the inner sphere solvent-assisted hydrolysis transition state TS[7a8a] reported in Figure 4. The main difference is that in TS[1a-11] the chain more closely resembles an $\mathrm{H}_{5} \mathrm{O}_{2}{ }^{+}$ unit, hydrogen bonded to the $\beta$-hydroxy-ethyl group, attacking the methyl group, rather than the hydroxyl ligand and two distinct water molecules of the inner sphere transition state. ${ }^{7}$ This small difference between the structures of the transition states is reflected in the similar energy barriers of the outer and inner sphere solvent-assisted mechanisms (16.9 vs $20.3 \mathrm{kcalmol}^{-1}$, respectively, relative to $\mathbf{1}){ }^{7}$ The methyl group $\mathrm{C}-\mathrm{Pd}$ distance is already stretched to $2.11 \AA$ from its initial $2.05 \AA$. This distance then further increases to $2.33 \AA$, while the $\mathrm{H}-\mathrm{Pd}$ distance decreases to $1.90 \AA$ as the methyl group becomes an agostically bound methane in the product.

Given the uncertainties in our approach, we are not able to determine whether the water-assisted "inner sphere" mechanism with prior hydrolysis of the $\mathrm{Pd}-$ $\mathrm{CH}_{3}$ bond, Figure 3, or the "outer sphere" water-assisted nucleophilic attack on ethylene, Figure 5, is the more facile pathway to the $\beta$-hydroxy-ethyl complex $\mathbf{2}$ from the $\mathrm{Pd}(\mathrm{II})$-based Brookhart resting state 1. However, both pathways seem to be more facile than the waterunassisted route described in Figure 2.

After the discussion of ways leading to the $\beta$-hydroxyethyl complex $\mathbf{2}$, our focus will now shift to ways in which 2 can isomerize to either 5 or 6 (Scheme 1) followed by an exploration of pathways that can convert 5 and 6 into aldehyde and $\operatorname{Pd}(0)$ by proton abstraction, Scheme 1.

Exploration of Isomerization Pathways for the $\beta$-Hydroxy-ethyl Complex 2 Leading to the $\alpha$ Hydroxy-ethyl System 5 or the Hydrido Aldehyde Complex 6 without Water Assistance. The first step in the isomerizaion process for $\mathbf{2}$ is a $\beta$-hydrogen elimination step that transforms $\mathbf{2}$ to the hydrido hydroxy-ethylene complex $\mathbf{3}$ with an internal barrier of $16.9 \mathrm{kcal} \mathrm{mol}^{-1}$ and a reaction enthalpy of $1 \mathrm{kcal} \mathrm{mol}^{-1}$, Figure 7. Insertion of the hydroxy-ethylene ligand into the $\mathrm{Pd}-\mathrm{H}$ bond results next in an $\alpha$-hydroxy-ethyl complex 4 with an internal barrier of $4.6 \mathrm{kcal} \mathrm{mol}^{-1}$ and an enthalpy of $-1.4 \mathrm{kcal} \mathrm{mol}^{-1}$.

(23) Eisenstein, O.; Hoffman, R. J. J. Am. Chem. Soc. 1981, 103 (15) $4308-4320$. 


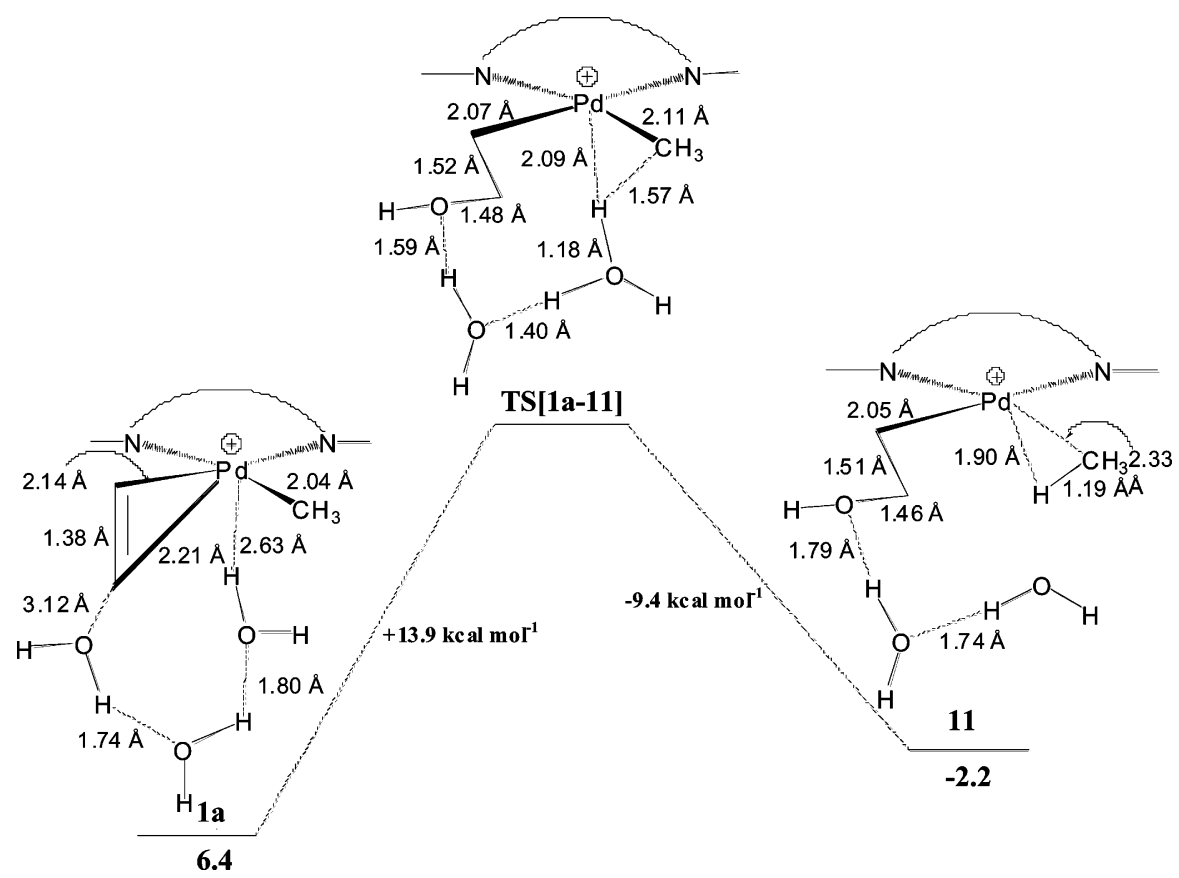

Figure 6. Structural changes in the conversion of $\mathbf{1 a}$ to $\mathbf{1 1}$.

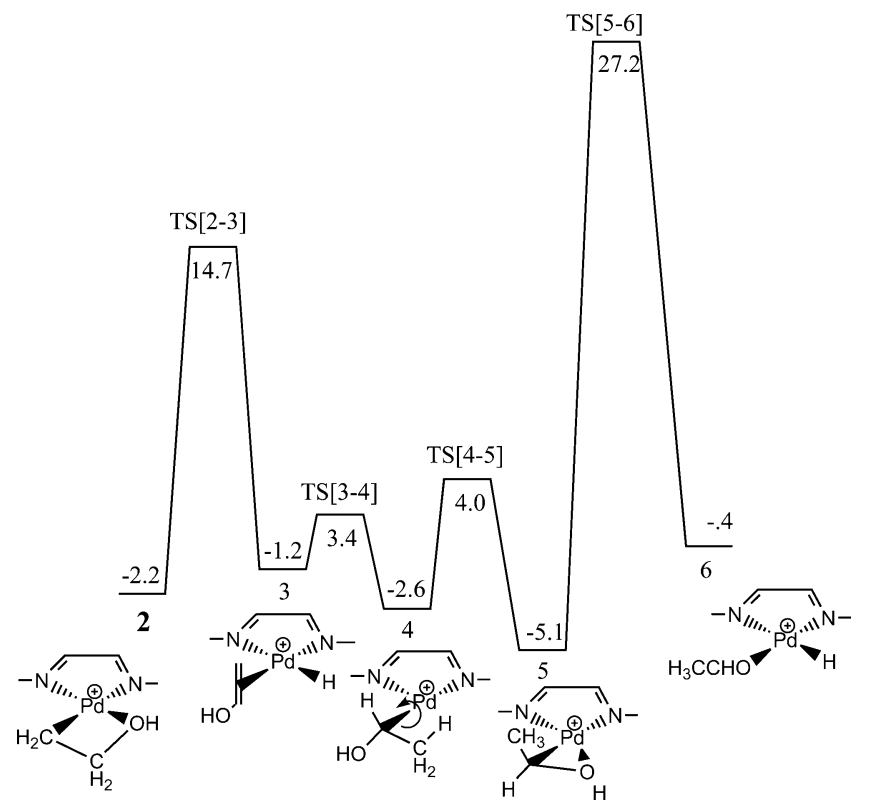

Figure 7. Potential energy surface for the isomerization of 2 to 6 .

The entire process $\mathbf{2} \rightarrow \mathbf{4}$ corresponds to an isomerization of the $\beta$-hydroxy-ethyl complex 2 to the $\alpha$ hydroxy-ethyl complex 4 by "chain walking" involving isomerization via $\beta$-hydrogen elimination. ${ }^{2}$ The isomerization is exothermic by $-0.4 \mathrm{kcal} \mathrm{mol}^{-1}$. Finally 4 can isomerize to the oxygen chelate $\mathbf{5}$ by the rotation around the $\mathrm{Pd}-\mathrm{C}_{\alpha}$ bond. The oxygen chelate 5 is the most stable $\alpha$-hydroxy-ethyl complex with an energy of $-5.1 \mathrm{kcal}$ $\mathrm{mol}^{-1}$ compared to $\mathbf{1}$.

The $\alpha$-hydroxy-ethyl complex $\mathbf{4}$ is favored over the $\beta$-hydroxy-ethyl complex 2 because the alkyl radical in 4 is more stable than in 2 by $0.5 \mathrm{kcal} / \mathrm{mol}$ according to our calculations. The complex $\mathbf{5}$ is further stabilized by the oxygen chelate interaction. We finally have the transformation of $\mathbf{5}$ to the hydride aldehyde complex 6.
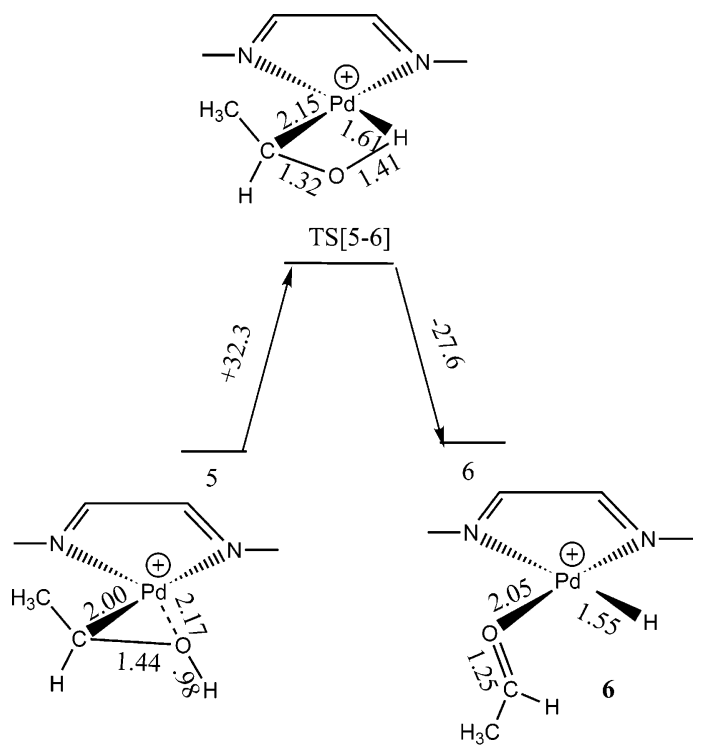

Figure 8. Structural changes in the conversion of 5 to 6.

Figure 8 shows some geometric details of molecules 5 and $\mathbf{6}$, as well as the transition state connecting the two molecules. In molecule 5 the $\mathrm{Pd}-\mathrm{C}$ bond is $2.00 \AA$, compared to $2.17 \AA$ for the "coordinate-covalent" $\mathrm{Pd}-\mathrm{O}$ bond; as we might expect, the former is shorter than the latter. Furthermore, the $\mathrm{Pd}-\mathrm{C}$ bond is directly opposite the coordinating $\mathrm{N}$ atom, showing that from an energetic point of view the $\mathrm{Pd}-\mathrm{C}$ bond takes precedence over the $\mathrm{Pd}-\mathrm{O}$ bond (the $\mathrm{Pd}-\mathrm{O}$ bond is not located at one of the "ideal" sites in the square planar complex). A simple linear transit run, involving rotation of the ligand about the $\mathrm{Pd}-\mathrm{C}$ bond axis, $\mathbf{5} \rightarrow$ TS $[4-5]$, shows that only $\sim 9 \mathrm{kcal} \mathrm{mol}^{-1}$ is required to break the $\mathrm{Pd}-\mathrm{O}$ bond. The $\mathrm{C}-\mathrm{O}$ distance is $1.44 \AA$; hence this is a single bond. This bond length is nearly identical to the $\mathrm{C}-\mathrm{O}$ distance in methanol, $1.43 \AA{ }^{24}$ In the product

(24) Lide, D. R. CRC Handbook of Chemistry and Physics, 84th ed.; CRC Press: Boca Raton, FL, 2003-2004. 


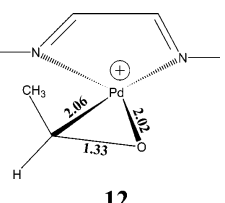

12

Figure 9. Structural details of acetaldehyde bound to the neutral catalyst.

6, the acetaldehyde molecule is coordinated to the $\mathrm{Pd}$ center through its $\mathrm{O}$ atom. The $\mathrm{Pd}-\mathrm{O}$ distance has now shortened to $2.05 \AA$, and the $\mathrm{C}-\mathrm{O}$ distance has shortened to $1.25 \AA$, close to the value in free acetaldehyde $(1.210 \AA){ }^{24}$ The transition state connecting $\mathbf{5}$ and $\mathbf{6}$, TS[5-6], exhibits a $\mathrm{C}-\mathrm{O}$ distance of $1.32 \AA$, between a single and double bond distance. Meanwhile, the $\mathrm{O}-\mathrm{H}$ bond has rotated "up" into the "square-plane" coordination of the $\mathrm{Pd}$ atom and lengthened from $0.98 \AA$ to 1.41 $\AA$; the $\mathrm{Pd}-\mathrm{H}$ distance of $1.61 \AA$ is near its final resting value of $1.55 \AA$ in $\mathbf{6}$.

Alternative Generation of 6 from 3. Vinyl alcohol (VA) is known "readily" to isomerize to acetaldehyde (AA). ${ }^{25 a}$ In fact special care must be taken in order to avoid such an isomerization. The driving force here is the $11 \mathrm{kcal} \mathrm{mol}^{-1}$ higher stability of AA compared to VA. ${ }^{25 b}$ However the same thermodynamical driving force is absent for coordinated AA (complex $\mathbf{3}$ ) compared to coordinated VA (complex $\mathbf{6}$ ) since $\mathbf{3}$ is more stable than 6 by $\sim 1 \mathrm{kcal} \mathrm{mol}^{-1}$, Figure 7 . We have nevertheless explored a direct concerted path in which the hydroxy hydrogen in $\mathbf{3}$ migrates to the unsubstituted olefin carbon to produce $\mathbf{6}$. The barrier for such a migration was calculated to be $55.3 \mathrm{kcal} \mathrm{mol}^{-1}$, which is even higher than for the route $\mathbf{3} \rightarrow \mathbf{4} \rightarrow \mathbf{5} \rightarrow \mathbf{6}$, where the highest barrier associated with TS[5-6] is $32.3 \mathrm{kcal} /$ $\mathrm{mol}^{-1}$. Our finding is not surprising since Nagaoka et al. ${ }^{25 \mathrm{~b}}$ found a barrier of $56.2 \mathrm{kcal} / \mathrm{mol}^{-1}$ for the concerted and unsupported isomerization of vinyl alcohol to acetaldehyde in the gas phase. It is thus clear that the facile isomerization of vinyl alcohol to acetaldehyde observed experimentally must be assisted in some way, ${ }^{25 b}$ as we shall discuss later.

We have seen that the formation of the $\alpha$-hydroxyethyl complex $\mathbf{5}$ from $\mathbf{2}$ is a relatively facile process, whereas the isomerization from 2 to the hydrido aldehyde system 6 appears to be less feasible. With this in mind, we shall now explore ways in which 5 can decompose to aldehyde and $\operatorname{Pd}(0)$ by proton loss, Scheme 1. Provided that such a process is facile, the exploration of decomposition paths involving $\mathbf{6}$ is less urgent. Nevertheless, we shall also examine such routes and briefly discuss ways in which the barriers can be reduced for the isomerization of $\mathbf{5}$ to $\mathbf{6}$ by the assistance of one or two water molecules.

Proton Loss from 5 or 6 to a Water Cluster. We first consider release of the $\mathrm{COH}$ proton from $\mathbf{5}$ to a water cluster in the emulsion to form a neutral $\mathrm{Pd}^{0}$ complex with acetaldehyde attached. We found only one stable structure on the potential energy surface, in which the acetaldehyde is bound as an $\eta^{2}$ ligand, 12 (Figure 9). The angle $\mathrm{N}-\mathrm{Pd}-\mathrm{C}$ is $123.0^{\circ}$, and that of the $\mathrm{N}-\mathrm{Pd}-\mathrm{O}$ framework is $125.2^{\circ}$. Such a structure is

(25) (a) Capon, B.; Guo, B.-H.; Kwok, F. C.; Siddhanta, A.K.; Zucco, C. Acc. Chem. Res. 1988, 21, 135. (b) Nagaoka, M.; Suenobu, K. Yamabe, T. J. A. Chem. Soc. 1997, 119, 8023. reminiscent of $\mathrm{L}_{2} \mathrm{M}\left(\eta^{2}-\mathrm{O}_{2}\right)$ complexes of $\mathrm{Pd}$ and $\mathrm{Pt} .{ }^{26-29}$ The total binding energy of the ligands to $\mathrm{Pd}$ is 79.4 kcal mol ${ }^{-1}$ (gas phase). The $\eta^{2}$-acetaldehyde is bound to the (diimmine) $\mathrm{Pd}^{0}$ substrate by $42.4 \mathrm{kcal} \mathrm{mol}^{-1}$ (gas phase). Hence, this ligand is more strongly bound than the 15-20 kcal mol${ }^{-1}$ computed for $\left(\mathrm{PH}_{3}\right)_{2} \mathrm{Pd}\left(\eta^{2}-\mathrm{O}_{2}\right)$ and $\left(\mathrm{PH}_{3}\right)_{2} \mathrm{Pd}\left(\eta^{2}-\mathrm{C}_{2} \mathrm{H}_{4}\right)$ complexes. ${ }^{30}$ However, this binding energy of the ligands to the $\operatorname{Pd}(0)$ atom needs to be put into context: formation of palladium black from free palladium atoms (gas phase) is exothermic by $90.4 \mathrm{kcal}$ $\mathrm{mol}^{-1}, 31$ making loss of the ligands and formation of palladium black exothermic by $11 \mathrm{kcal} \mathrm{mol}^{-1}$.

Deprotonation of 5 to produce 12 results in a shortening of the $\mathrm{C}-\mathrm{O}$ and $\mathrm{Pd}-\mathrm{O}$ bonds. This is expected because of the excess electron density now resident at the oxygen atom. Meanwhile, the $\mathrm{Pd}-\mathrm{C}$ bond has lengthened, again as expected.

The deprotonation of $\mathbf{6}$ by abstracting a proton from the metal center leads quite readily to the same product $\mathbf{1 2}$ as the deprotonation of $\mathbf{5}$. The aldehyde unit already present in $\mathbf{6}$ now experiences an elongation of the $\mathrm{C}=\mathrm{O}$ bond due to metal-to-ligand back-donation as aldehyde goes from a $\eta^{1}-\mathrm{Pd}(\mathrm{II})-\mathrm{OC}(\mathrm{H}) \mathrm{CH}_{3}$ coordination in 6 to a $\operatorname{Pd}(0)-\eta^{2}$-acetaldehyde coordination in $\mathbf{1 2}$.

Energetics and Kinetics of Proton Removal from 5 or 6. This is the critical part of the discussion. We shall now examine the energetic feasibility of reducing 5 and 6 to the common $\operatorname{Pd}(0)$ complex 12 by proton abstraction.

Formation of a hydronium ion in aqueous solution from an acid is thought to be a process with no kinetic barrier. Therefore, in the discussion in this section, we primarily seek to understand the thermodynamics of proton transfer to the aqueous phase of the emulsion from 5 or 6. There have been two values that have appeared in the past 10 years for the proton's enthalpy of solvation in aqueous media: $-267.28^{32 \mathrm{a}}$ and $-274.88^{33 \mathrm{~b}}$ kcal mol-1. We shall use the former, as it has been adopted by Pearson ${ }^{33}$ and others in their studies on the acidity of transition metal hydrides. Applying this number affords an enthalpy of $\Delta E=-8.1 \mathrm{kcal} \mathrm{mol}^{-1}$ for the loss of a proton from $\mathbf{5}$ in a toluene suspension, with the corresponding values for $\mathbf{6}$ given by $-12.8 \mathrm{kcal}$ $\mathrm{mol}^{-1}$. The exothermic deprotonation of both $\mathbf{5}$ and $\mathbf{6}$ would indicate that both species are strong acids. This is line with the findings of Pearson, ${ }^{33}$ who has shown that metal hydrides can have $\mathrm{p} K_{\mathrm{a}}$ values as low as -8 , corresponding to a deprotonation enthalpy of $-11 \mathrm{kcal}$ $\mathrm{mol}^{-1}$.

(26) Kudo, T.; Gordon, M. S. J. Phys. Chem. A 2002, 106, $11347-$ 11353.

(27) Becerra, R.; Goldberg, N.; Cannady, J. P.; Almond, M. J.; Ogden, J. S.; Walsh, R. J. Am. Chem. Soc. 2004, 126, 6816-6824.

(28) Lewis, M. J. Phys. Chem. A 2003, 107, 6814-6818.

(29) Collman, J. P.; Hegedus, L. S.; Norton, J. R.; Finke, R. G. Principles and Applications of Organotransition Metal Chemistry; University Science Books: Mill Valley, CA, 1987; p 203.

(30) Li, J.; Schreckenbach, G.; Ziegler, T. Inorg. Chem. 1995, 34, 3245 .

(31) (a) Enthalpy of formation of palladium black. Physical Chemistry Reference Data 1982, 11 (suppl. 2). (b) Dasent, W. E. Inorganic Energetics: An Introduction, 2nd ed.; Cambridge University Press: Cambridge, 1982.

(32) (a) Tawa, G. J.; Topol, I. A.; Burt, S. K.; Caldwell, R. A.; Rashin A. A. J. Chem. Phys. 1998, 109 (12), 4852-4863. (b) Tissandier, M. D.; Cowen, K. A.; Feng, W. Y.; Gundlach, E.; Cohen, M. H.; Earhart A. D.; Coe, J. V.; Tuttle, T. R. J. Phys. Chem. A 1998, 102 (40), 77877794 .

(33) Pearson, R. G. Chem. Rev. 1985, 85, 41. 
At this stage we have the neutral molecule $\mathbf{1 2}$ and hydronium ion in solution. As mentioned above, though the two ligands (diimine and acetaldehyde) are bound to the $\mathrm{Pd}(0)$ atom by about $80 \mathrm{kcal} \mathrm{mol}^{-1}$, approximately $40 \mathrm{kcal} \mathrm{mol}^{-1}$ for the acetaldehyde alone, formation of palladium black from free palladium atoms is exothermic by $90 \mathrm{kcal} \mathrm{mol}^{-1}$, making decomposition of the $\operatorname{Pd}(0)$ complex a favorable process.

We are not able to simulate the entire reaction profile for the deprotonation of $\mathbf{5}$ and $\mathbf{6}$ in bulk water. However we were able to obtain the profile of deprotonation of $\mathbf{5}$ and 6 to respectively a single water or a water dimer. We find in both cases that the process lacks a kinetic barrier, as one would expect from a simple acid-base reaction.

In view of the findings here we are led to suggest that the isomerization of the $\beta$-hydroxy-ethyl complex 2 to the $\alpha$-hydroxy-ethyl isomer $\mathbf{5}$ (Scheme 1) followed by deprotonation of 5 to the $\operatorname{Pd}(0)-\eta^{2}$-acetaldehyde complex 12 (Figure 9) and subsequent decomposition to acetaldehyde and palladium black represent a relatively facile decomposition route of the Pd(II)-based Brookhart catalyst in an aqueous medium after addition of ethylene. Further, although the deprotonation of $\mathbf{6}$ is also feasible, it is not in any way more viable. Thus, there is not any real advantage in invoking $\mathbf{6}$ as an intermediate in the decomposition of $\mathbf{1}$. In fact if we were to find a facile isomerization route from either $\mathbf{3}$ or 5 to $\mathbf{6}$ with a low barrier $\left(<10 \mathrm{kcal} \mathrm{mol}^{-1}\right)$, that would entail that any quantity formed of $\mathbf{6}$ in time would convert to the much more stable isomer 5, Figure 7. Nevertheless we shall in the next section briefly discuss waterassisted isomerization pathways leading from 5 to 6 .

Water-Assisted Isomerization Pathways Leading from 5 to 6. We have explored ways in which one or two water molecules might assist the isomerization of 5 to 6 . The first water lowers the isomerization barrier by $5.3 \mathrm{kcal} \mathrm{mol}^{-1}\left(\mathbf{T S}[\mathbf{5}-\mathbf{6}]-\mathbf{H}_{\mathbf{2}} \mathbf{O}\right)$, whereas adding a second water lowers the barrier $\left(\mathbf{T S}[\mathbf{5}-\mathbf{6}]-\mathbf{2} \mathbf{H}_{2} \mathbf{O}\right)$ by another $3 \mathrm{kcal} \mathrm{mol}^{-1}$ to $24.0 \mathrm{kcal} \mathrm{mol}^{-1}$. Our model with two water molecules already has three oxygen atoms, with two protons shuttling between the three oxygen atoms. Therefore, our model system is equivalent in this sense to the case that Siegbahn considered with three water molecules. ${ }^{3,4}$ Siegbahn observed in his model studies that the addition of further water molecules did not have a significant effect on the barrier. Although we have not studied additional water molecules, we have observed above that the geometry of complexation seems already to be ideal with two water molecules. That is, the strong hydrogen bonds are nearly linear for maximum bonding effect. On this basis we do not believe that adding an additional water molecule in this study would have a significant effect on lowering the barrier for proton transfer.

Nagaoka et al. ${ }^{25 b}$ have in an extensive theoretical treatment involving both ordinary electronic structure calculations and molecular dynamics (MD) shown that vinyl alcohol (VA) can isomerize to acetaldehyde (AA) in a process catalyzed by a hydronium ion with a barrier of $15 \mathrm{kcal} \mathrm{mol}^{-1}$. It is possible that a similar isomerization pathway exists for $\mathbf{3}$ going to $\mathbf{6}$, perhaps with an even smaller barrier. However, in that case the thermodynamical driving force would be reversed and the

\section{Scheme 3. Water-Assisted Transition States TS[5-6]- $\mathrm{H}_{2} \mathrm{O}$ and TS[5-6]-2 $\mathrm{H}_{2} \mathrm{O}$ for the Isomerization of 5 to 6}

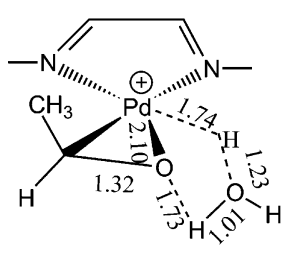

TS[5-6]- $\mathrm{H}_{2} \mathrm{O}$

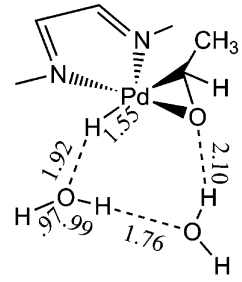

TS[5-6]-2 $\mathrm{H}_{2} \mathrm{O}$ concentration of $\mathbf{6}$ would be small compared to $\mathbf{3}$ and negligible compared to $\mathbf{5}$. We have not undertaken such a massive endeavor, as neither the existence nor lack of a low barrier for the $\mathbf{3}$ to $\mathbf{6}$ interconversion would challenge the conclusion that the final decomposition to acetaldehyde and palladium black is likely to take place from $\mathbf{5}$ in a deprotonation step.

\section{Conclusions}

Previous experimental investigations ${ }^{1}$ have explored the feasibility of coordination polymerization in aqueous media with ethylene as the monomer and the cationic Pd(II)-based diimine Brookhart system as catalyst. It was found that the Brookhart catalyst before addition of ethylene could survive for some time in aqueous media. However, on addition of ethylene to form $\mathbf{1}$, the system would readily decompose under the deposition of palladium black.

We have in the current investigation studied a possible mechanism for the decomposition of the Brookhart catalyst after ethylene addition. The first step in the mechanism consists of the conversion of $\mathbf{1}$ into a $\beta$-hydroxy-ethyl complex $\mathbf{2}$ by water. A possible pathway for this step is the external attack of a chain of three water molecules where one end of the chain transfers a proton to the $\mathrm{Pd}-\mathrm{CH}_{3}$ bond under formation of methane, whereas the other end attacks the coordinated ethylene with a $\mathrm{OH}$ group under generation of the $\beta$-hydroxy-ethyl complex 2, Figure 5 . This path has an estimated enthalpic barrier of $20.3 \mathrm{kcal} \mathrm{mol}^{-1}$ relative to 1 . Alternatively, the chain of three waters displaces ethylene and hydrolysis of the $\mathrm{Pd}-\mathrm{CH}_{3}$ bond occurs under formation of a hydroxy complex $\mathbf{9 a}$ and methane, Figure 3. A subsequent coordination of ethylene and insertion into the $\mathrm{Pd}-\mathrm{OH}$ bond affords again the $\beta$-hydroxy-ethyl complex 2 . The enthalpic barrier for this path is $16.9 \mathrm{kcal} \mathrm{mol}^{-1}$ relative to 1 . It was not possible conclusively to point to one of the two paths as the prevalent mechanism due to uncertainties in the free energy required to produce a water chain in an aqueous medium.

The $\beta$-hydroxy-ethyl complex 2 can readily isomerize to the hydrido vinyl alcohol system $\mathbf{3}$ as well as two forms of a $\alpha$-hydroxy-ethyl complex. Here the first form has an interaction between palladium and a $\beta$-hydrogen (4), whereas the second has a $\mathrm{Pd}-\mathrm{O}$ chelating bond involving the $\alpha$-hydroxy oxygen (5). The most stable species is 5, which is $2.9 \mathrm{kcal} \mathrm{mol}^{-1}$ lower in energy than 2. The $\alpha$-hydroxy-ethyl complex $\mathbf{5}$ can deprotonate under the formation of the $\mathrm{Pd}(0)-\eta^{2}$-acetaldehyde complex $\mathbf{1 2}$ 
(Figure 9). This process is exothermic by $-8.1 \mathrm{kcal}$ $\mathrm{mol}^{-1}$. Once the neutral complex $\mathbf{1 2}$ is formed, decomposition to acetaldehyde and palladium black is possible with an exothermicity of $11 \mathrm{kcal} \mathrm{mol}^{-1}$.

Vinyl alcohol (VA) isomerizes ${ }^{25}$ readily to acetaldehyde (AA) via an acid-catalyzed process with a barrier of $15 \mathrm{kcal} \mathrm{mol}{ }^{-1}$. The driving force for this tautomerization is the fact that AA is $11 \mathrm{kcal} \mathrm{mol}^{-1}$ more stable than VA. One might have expected a similar isomerization for coordinated VA (3) to complexed AA (6). However in this case $\mathbf{3}$ is more stable than $\mathbf{6}$ by $0.8 \mathrm{kcal}$ $\mathrm{mol}^{-1}$ and $\mathbf{3}$ can isomerize further to $\mathbf{5}$, which is $4.7 \mathrm{kcal}$ $\mathrm{kcal} \mathrm{mol}^{-1}$ more stable than $\mathbf{6}$. Thus even if a low barrier of interconversion existed between $\mathbf{5}$ and $\mathbf{6}$ or between $\mathbf{3}$ and $\mathbf{6}$, the concentration of $\mathbf{6}$ would be negligible compared to $\mathbf{5}$. We did not actually find a facile interconversion route between $\mathbf{5}$ and $\mathbf{6}$ with a barrier below
$10 \mathrm{kcal} \mathrm{kcal} \mathrm{mol}{ }^{-1}$. Further, calculations on the deprotonation of $\mathbf{6}$ rather than $\mathbf{5}$ did not reveal any advantages. All these considerations led us to suggest that the final decomposition of $\mathbf{1}$ to palladium black and aldehyde takes place by deprotonation of the $\alpha$-hydroxyethyl complex $\mathbf{5}$.

Acknowledgment. This work has been supported by the National Sciences and Engineering Research Council of Canada (NSERC). R.D.K. wishes to acknowledge the donors of the American Chemical Society Petroleum Research Fund for partial support of this work. T.Z. thanks the Canadian Government for a Canada Research Chair. G-S. and S.M. thank the DFG for financial support (AM2Net: Me 1388-3). 